\title{
Mobile-Based Language Learning Community in Business English Independent Learning*
}

\author{
Ling Zhang \\ Beijing Wuzi University, Beijing, China
}

\begin{abstract}
Mobile-based language learning is an innovative approach for delivering electronically mediated, well-designed, learner-centred interactive learning environments by utilizing internet and mobile devices with respect to instructional design principles. M-learning is a natural extension of e-learning and has the potential to make learning even more widely available and accessible than we are used to in existing e-learning environments. This paper describes an upcoming language-learning project to examine the feasibility and limitation of Mobile-Assisted Language Learning (MALL) by building a mobile learning community that facilitates learning in a university environment. Three interviews are arranged at the beginning, during, and after the community learning as well as a questionnaire to acquire student perception toward MALL. The research will focus on student preference in community activities and task types to suggest a good learning model in mobile-based learning community and therefore shed some light on making suggestions for software technicians to design mobile apps especially for language teaching and learning.
\end{abstract}

Keywords: Mobile-Assisted Language Learning (MALL), community building, autonomous learning

Research suggests that $70 \%$ of Chinese university students spend more than 30 minutes a day sending messages on their mobile phones; and on average, 77\% spend more than 30 minutes browsing the internet, applying app to acquire information on their mobile phones (Chinamobile, 2012). There is a high degree of correlation between the language proficiency and the time spent on reading in that language. So we can imagine that if students were to engage in reading on their phone for just a small portion of this time, it could be inferred that measurable improvements in their reading ability could be attained.

In China, the discussion of applying mobile phone resource in language learning has been fascinating people for decade. But the application of theories into education is still on its very early stage. Mobile-based language learning is either new to education in general, or to the language field in particular. This situation maybe partly caused by the fact that a big proportion of English researchers and practitioners do not have personal experiences of applying the newly developed mobile technologies on language learning. While mobile technology, such as the touch-based smart-phone, has become part of our daily lives. The popularity of mobile phone in acquiring information by connecting to the internet makes it impossible that we ignore its application in language education. This paper is planning to take a look at the learning outcomes of Mobile-Assisted

\footnotetext{
* This work was supported by the project "Beijing Higher Education Young Elite Teacher Project”. The project number is "yetp1534".

Corresponding author: Ling Zhang, MA, senior lecturer, Beijing Wuzi University, Beijing, China; research field: technology-assisted language acquisition. E-mail: irene_zhangling@hotmail.com.
} 
Language Learning (MALL) and examining the learning outcome of the mobile-based learning community. Since learners' participation is the key part of collaborative learning within the community, which is a big concern of the author because Chinese learners are more modest and shy to express themselves. As study shows that the majority of university students in China come from an educational background in which the traditional roles of teacher and learner are still generally accepted. The traditional culture teaches them that teacher is in control and makes all the decisions regarding the content, material selection, and learning directions. The issue of Chinese educational system is discussed so many times by EFL (English as a Foreign Language) professionals (Hsu, 2005), but the situation has not been dramatically changed. Under this circumstance, students fail to take responsibility in their L2 acquisition process which leads an unsatisfied result in their participation in learning community and therefore, in their independent learning outcomes. The research is trying to seek some suggestions to improve social participation of learner to obtain better learning outcomes.

\section{The Aims of the Study}

Since the topic of this dissertation is concerning mobile technology which is up-dated day by day, it is hard to find a published literature in this area except on-line articles. Due to lack of relevant book on Chinese learner with MALL, the writer of this paper aims to answer the following questions:

(1) What kind of materials and task types are favoured by the students?

(2) What are the student perceptions toward MALL community?

(3) What factors will affect the participating behaviours of learners in application of mobile in improving language skills in Chinese universities? What are the reasons of non-participation and negative participation in using mobile after class?

\section{Literature Review}

The literature review is divided into four sections, each focuses on a particular aspect central to the current study. The first section views mobile as a language learning tool and its strengths and weaknesses in community learning. The following section examines to what extent mobile can be applied in L2 acquisition after class based on the theory of participation. The third part concerns the relationship between mobile and independent learning.

\section{Mobile-Based Language Learning and Community}

The MALL study started from 1994, but it has become a hot topic from the emergence of smart phone which has a Wi-Fi device to connect to the internet and make the real time on-line communication possible since 2006. As the technology advances, some critical toward the limitation of mobile phone have been settled by the emergence of new functions of smart phone. For instance, the technologies of Wi-Fi, 3G, and even 4G networks broaden the small bandwidth problem. Similarly, problems associated with manual text input are being resolved through the use of speech recognition technology and touch screens (Wang \& Smith, 2013). Since the emergence of smart phones in 2007, more and more functions specific to PCs (personal computers) and other hand-held devices have been integrated within mobile phone devices. The advancement of the mobile technologies makes it more suitable to be a language learning tool. Numerous researches have recommended MALL as a method of providing learners real time collaborative learning experience. It has been shown that mobile phones are increasingly used for improving knowledge of vocabulary (Stockwell, 2010; Zhang, Song, \& Burston, 2011), grammar (Sung, Huang, \& Chang, 2006; Li \& Hegelheimer, 2013), listening (Liu \& Chu, 2010), 
and speaking (Rueckert, Kiser, \& Cho, 2012), other than the four basic language skills, mobile phones can also be applied to other learning situations, such as foreign culture acquisition (Comas-Quinn \& Mardomingo, 2009).

Smart phone is employed as a language learning tool in many fields to improve learners' language skills. For example, in the vocabulary acquisition field, some research (Zhang et al., 2011) is done to compare mobile-based vocabulary acquisition with paper-based one, the results show that students who learn through mobiles are found to learn more words than the ones do the paper-based tasks. Students have a positive attitude toward mobile-based language learning community. And numerous advocates have recommended MALL as a method of providing L2 learners with rich, real time, cooperative, and conversational experiences both inside and outside the classroom.

But it is impossible to reach a consensus for all the researches in MALL. Notwithstanding its benefits, MALL also poses related challenges. There are some side effects need to take into consideration when a mobile-based language community is built. For example, compare with computer, mobiles have limited audiovisual quality, virtual keyboarding and one-finger data entry, and limited power. Except from the technological weaknesses, Colpaert pointed out a paradox of MALL, which is while mobile technologies are advancing, their output is quickly moving from verbal to visual, a clear disadvantage for language learning (Colpaert, 2004).

Through the analysis of the negative effects of MALL, Wang and Smith (2013) argued that some criteria must be followed in mobile-based learning to play to its strengths and compensate the weaknesses. The criteria include: (1) providing engaging learning materials that are not too long; (2) a proper degree of teacher monitoring; (3) student involvement; (4) the need for incentives; and (5) a respect for privacy (Wang \& Smith, 2013).

Students are very reluctant to concentrate on the long and exhausting materials, they usually have a short attention span on the mobile learning materials. Delivering smaller chunks of materials—such as mini-essays and grammar quizzes - may be more suitable for better mobile phone learning experiences (Wang \& Smith, 2013). And in the mobile-based learning community, the learning outcome is guaranteed by the degree of student involvement. But we cannot expect students automatically take part in the teaching and learning activities, so there must be some levels of teacher supervision and some rewards or incentives to seduce them into it, such as the credits. Other than this, the learning materials need to be related to the assessment to "push" student to learn.

The environment of the learning community is also an influencing factor to learner participation. People are very reluctant to express themselves in a group when the members are strangers. They have a fear that there will be retribution when they say something wrong, or in other words, the communication environment is neither open nor safe. A mutual trust need to be found among the group members. So there maybe some additional criteria to follow: (1) design assessments according to the learning material; (2) mutual trust among group members; and (c) prompt feedbacks from teachers are needed.

\section{Participation in MALL Community}

Based on the former discussions of the pedagogical application of mobile, it has most motivating factors for language learning, but to improve the communicative competence, the deciding factor is the participation of the learners especially in the independent learning environment. Therefore, the nature of participation is discussed in this section. 
As the updating of the language learning theories, learner's role changes from a receiver to a participant. The theory first introduced by Sfard (1998), she distinguished the acquisition metaphor from the participation metaphor for learning. As she said,

The acquisition metaphor refers to learning which is a matter of individual construction and acquisition. The goal of learning is individual enrichment. While the participation metaphor of learning refers to learning as a process of participation in shared learning activities and social processes of knowledge construction. The goal of learning is community building.

The language learning changed from an individual activity to a social one. In this statement, Sfard (1998) described the feature of learning as "interactive", which is a higher level from individual. But "interactive" is not enough for learners when they have to work together to resolve the problem in language learning, which is called "collaborative".

Here we come to the different levels of participation in MALL. Different from the traditional paper-based language learning, learners in MALL can participate in the learning process by interacting with others through publishing and commenting; or can simply participate by making good use of the functionality of mobile materials through just reading and listening. As Nonnecke and Preece (2003) stated, lurking, a one-way participation, provides a sense of belonging regardless of whether they ever intend to participate. Learners can "learn" from participating the MALL at different levels no matter they commenting or just lurking.

Bates (1997) summarized in his work that the "participation" has two traits:

Individual nature-------isolated activity-----interaction with the learning materials

Social nature------------social activity-------interaction with people

In the learning process, learners cannot always be "individual”. There must be social interaction involved to fulfil the human nature. With the tasks introduced into the MALL community, learners would work together to deal with the tasks to find the answer. In the MALL community, the participation needs to be pushed from just individual level to social level to yield a better learning outcome at the group level. As Harasim, Hiltz, Teles, and Turoff (1995) defined that collaborative learning is "a learning process where two or more people work together to create meaning, explore a topic, or improve skills". At the outset of this review, it must be acknowledged that collaborative learning is a complex concept and not a clearly defined one. For the author, the key concern of community learning is, as Panitz (1996) viewed, to facilitate accomplishment of an end product or goal through people working together in groups. According to this, the goal-driven nature of MALL community should be obviously labelled. It is necessary to set a goal before you build a community and, during the community study, measure the progress of community against the pre-set goal.

\section{The Independent Learning}

Class hours are far from enough for grasping a foreign language which needs constant practice to make it perfect. It is well-known by the L2 teachers that cultivating student the autonomous learning skills have significantly influenced EFL language education.

In the late 1970s, in a report that Holec (1981) was commissioned to write for the Council of Europe, he defined autonomy as "the ability to take charge of one's learning" (Holec, 1981). He highlighted that learners have to work within a learning structure which enables them to exercise their ability to take control of their learning. According to Holec, to take charge of one's learning means to be responsible for all the decisions related to the learning process. Independent learners are better able to understand what is being taught, achieve 
learning objectives, monitor their own learning, and use appropriate learning strategies (Hsu, 2005). In light of these findings, "independence" and "autonomy" imply that students take a greater degree of control over the content and methods of learning than is usual in classroom language learning contexts and to develop their integrated language skills.

While when it comes to the deeper connotation of “independent learning”, Berge (1995) opened another door as he put emphasis on the notion of cooperate with others as a socially responsible person. These definitions show mainly on the result of independence as cooperation while others may put more attention on the results of independent as being alone. So this defines "independent learning” as social activity rather than individual.

The MALL community offers students a collaborative and social way to carry out their independent learning since mobile is a social tool itself. The inherent social nature of mobile makes mobile-based learning community a clear and social label on it.

\section{Methodology}

\section{The Community Design}

(1) Period: The study is planned to be finished within one semester;

(2) Participants: 60 second-year college students (English major);

(3) Activities:

(a) Build up a learning community between teacher and learners through the mobile app "WeChat". The software is chosen because of its popularity and its distinguish feature-verbal entry. Teacher is the founder of this community by setting up the group. In this community, different tasks are set to encourage learners' participation in a social and collaborative way. Learners can publish their ideas and comments by resolving the pre-set tasks in this task-based language learning environment or even they can post their own questions or tasks to form a small sub-community;

(b) Analysis of the participation. Use the record of participants to analyse the participation of the learners in the experiment.

\section{The Development of MALL Materials}

The initial reading materials used within this project were chosen from the business English database which is developed by ESP (English for Specific Purposes) teachers team in Beijing Wuzi University. The materials in the database are classified in themes cover all the major topics in business English textbooks such as marketing, accounting, or logistics. In order to appeal to a majority of second-year students, whose knowledge of business English is at a pre-intermediate level, all the materials were rewrited into a simple and easy-to-understand manner. All the materials chosen have less than 10 new words, the difficult words are annotated with Chinese translations. Vocabulary notes were placed at the beginning of the essay to make readers aware of new vocabulary items before they read the essay (Wang \& Smith, 2013). To fit the essay to the limited screen of the mobile, all the chosen materials are short. All the tasks and quiz are designed out of the materials, the students respondents are recorded in the teaching log.

\section{Interviews}

Six students were chosen in three groups to do the interviews which were arranged in three period of time, before, during, and after the experiments. 


\section{Questionnaire}

A questionnaire was designed to collect some detailed information of the participants and their perception toward mobile-based learning community. The information is collected to analyse the parameters such as English proficiency and identity of the learners, to what extent, would influence their attitude toward MALL. And most importantly, what factors will be helpful to improve student involvement. The questionnaire will consist four parts: the demographic information of learners, their English and computer proficiency, investigation about the task type and materials, and open questions about their attitude toward MALL.

As the questionnaire was partly delivered to their mobile phones, the mobile version of the questionnaire was limited to 15 short questions, 14 were multiple choice questions, and the last one was an open-ended question asking their perception about the project and mobile-based learning.

\section{Data Analysis}

The data are collected from the questionnaire and interviews, the data are jointly analysed under each research questions.

\section{Research Question 1: What Kind of Materials and Task Types Are Favoured by the Students}

The first part of the questionnaire is designed to examine what kind of materials is ranked highest. We can easily tell from the table that short English essay and trivia of business English were rated as the most read materials. Twenty-two percent (22\%) of the students rate short essay as their most reading materials, from the interviews we can summarize that the students who favor short essay because the essay is short and easy to understand, they can easily obtain business concept without struggling around the language points. With the help of the Chinese gloss before the essay, they can understand better of the business connotation within the essay. They felt confident in reading the short essay to acquire business English knowledge. The other 27\% of the students prefer trivia of the business English with its conciseness and informativeness. They can get a quick glance of the business terms and make a quick use in their language application. And the biggest part comes out is the video. Thirty-seven percent (33\%) of the students prefer to watch videos which are designed within 12 minutes, since it fits the attention span of students and helps to build a instant mind diagram of the concerned topic (see Table 1).

Table 1

Material Types

\begin{tabular}{lllllll}
\hline Materials & Short essay & Conversation & Case study & Trivia of business English & Video & Total \\
\hline Accesses & 13 & 5 & 6 & 16 & 20 & 60 \\
Percentage (\%) & 22 & 8 & 10 & 27 & 33 & 100 \\
\hline
\end{tabular}

Here is an example of the trivia.

Benchmarking is the process of comparing one’s business processes and performance metrics (商业表现) to industry bests or best practices from other industries. In the process of benchmarking, management identifies the best firms in their industry, and compare the results and processes of those to one's own. In this way, they learn why these firms are successful.

Task: please find out the key words in the description according to your own understanding.

In terms of the different essay topics, the highest ranked is business and life (28\%), the interview results tell us that students need to find out how business do with their daily life to push them further in business 
English learning. They know in this way that what they learned have a real life implication. And when business is related to real life, it became more interesting and pragmatic. The high ranks followed by cultural difference (20\%) and social gaffes (20\%), these materials are usually started from an awkward life experience which can best attract students' attention and provide stimulation for the reading. These findings about the ranking of the essay topic tell that learning through interesting materials is a more accepted way to start mobile-based business English learning (see Table 2).

Table 2

Essay Genres

\begin{tabular}{llll}
\hline & Topics & Accesses & Percentage (\%) \\
\hline & Culture differences & 12 & 20 \\
& Business concepts & 7 & 12 \\
Essays & Social gaffes & 12 & 20 \\
& Business \& politics & 4 & 7 \\
& Economics \& life & 17 & 28 \\
Total & Marketing and sales events & 8 & 13 \\
\hline
\end{tabular}

The essential work in building a community is designing collaborative tasks involve all the participants in the community. The theory of social constructivism was long introduced into education field, especially language education (Palincsar, 1998; Corden, 2001). Social constructivism focuses on an individual's learning that takes place because of their interactions in a community, but students would not get engaged automatically, they need the tasks serve as a media to get everyone in the learning process. To obtain a better learning outcome, teacher needs to analyse what collaborative task types are preferred by students and have a better learn outcome. As the results showed, half of the students (53\%) rank the jigsaw reading activities in the first place in terms of learning outcomes. According to the interview question "Why do you think jigsaw reading is most helpful collaborative activity?", the answers came as "It is quiet new to us", "It is interesting!", "I have to read my part very carefully before I can explain it to my partners”. We can see that in the jigsaw activities, the role of students was constantly changing as it went back and forth between teacher and learner. They all reckoned that: "I learned a lot by being a teacher" (see Table 3).

Table 3

Task Type

\begin{tabular}{lll}
\hline Task type & Accesses & Percentage (\%) \\
\hline Discussion & 8 & 13 \\
Jigsaw activity & 32 & 53 \\
brainstorming & 9 & 15 \\
Case-based activity & 11 & 18 \\
Total & 60 & 100 \\
\hline
\end{tabular}

Research Question 2: What Is the Student Perception Toward MALL Community

The second part of the questionnaire investigated the overall perception of the project by the students. For example, the question asked: How often do you read the learning materials published in the learning community? Forty-one (41) students (68\%) responded that they had read all of the posted materials, while 11 (20\%) said that they had read everything but they fail to finish all the tasks attached, and five (8\%) said that 
they read a small proportion of the materials because these are the only materials they can understand. The next question asked if the project was helpful in improving their English ability and business English concepts. Forty-eight (48) (81\%) reported positively, saying that they thought the project, in general, was helpful in developing their business English vocabulary and concept. While the next question is asked would you continue to use mobile as a self-study tool? About 54 (90\%) students have a positive attitude toward MALL as a self-study tool. Forty-eight (48) (81\%) reported they would use mobile phone as a language learning tool even after this project and would continue to use it in other disciplines. As shown from the results of the questionnaire, $80 \%$ of the students consider that the MALL is a useful and motivated way to carry out the language learning. And they can largely enjoy the fun in the learning process. It makes the process much simpler and interesting. And among the four basic language skills, most of the students consider that speaking is the most difficult one and group chat is a really good way to promote the oral skills which is quite necessary for the college students in China.

According to the questionnaire, the project was well-received by the students. But there is a fact that cannot be ignored is that certain proportion of students did not participate the learning process, or at least they are not participated in an active way as teacher expected.

In terms of other questions, in response to "Will you continue to take part in the WeChat-based learning community on your own when it was not required?”, only 35\% of the students gave positive answers. This means that most students only treated this learning activity as a regular after class assignment, instead of a platform for active daily language learning.

\section{Research Question 3: What Factors Will Affect the Participating Behaviours of Learners in Application of Mobile in Improving Language Skills in Chinese Universities? What Are the Reasons of Non-Participation and Negative Participation in Using Mobile in Language Learning Community}

In terms of participation in the community, every group has its own mix of quiet students and outspoken students. A quiet student might result from a variety of factors: shyness, boredom, comprehension difficulty, fatigue, intro-spectiveness or any number of effective disturbances. At the same time, if only two or three students are controlling the class conversation, your class might be missing out on a wealth of opinions and views that could be offered by these quieter students.

The reason behind the non-participation is analysed between the questionnaire and the interview to find out the correlation among participation and sex, computer literacy, language proficiency, or other affecting factors.

Based on the joint analysing of the questionnaire and interview, it gives an indication that learners' participation in MALL community has a relatively close relation with learners' language proficiency and computer literacy while less related with learners' sexual differences. According to the participation records, the active participants are usually with high English proficiency. They are more motivated and have more control in the community learning activities. When relate to the theory of "identity" (Norton, 2000), the identity of those students is more accepted in the community, they, therefore, would like to invest more in community activities.

We cannot analyse the Chinese learners' reaction to a new teaching method without analysing the Chinese education tradition, a biggest and most vexed issue in universities. During the interview, some students think highly of the new style of learning and teaching while the others give sharply negative opinion. In order to discover the reasons which stop learners from participating, the interview put more efforts on the sources of the 
negative points from the students. Therefore, the focus has been moved to the teaching method of state schools and universities. Traditionally, Chinese EFL teachers give more than enough emphasis on the acquisition of grammar and vocabulary without giving sufficient direction on the application. So as a result, when the students are asked to take part in the activities which need communicative or critical skills, they usually chose to back out, because they could not find a way to be a part of these activities.

\section{Discussion of Findings}

The user action log is used in this research to track students' participation by recording their browsing and interactive behaviour. In this way, it is possible to monitor the students' investment of time and effort. Building on this information, the assignment content adjustments and type selection could be made to improve learner engagement and, finally, optimize learning.

Besides these, in terms of promoting the learner participation, two key findings in the research need more attention.

\section{Safe Community Environment}

According to the interview and the open question, the community environment is essential for learner's participation. Whether they feel safe to participate is a defining factor for their participation. Learners must be able to express their opinions freely without fear of retribution, and feel that the discussion will be taken seriously. The learners might also need to agree whether politically sensitive topics of discussion should be kept within the confines of the team. So a free and safe environment counts for the participation of the learners in the community, especially for the ones with lower English proficiency.

\section{The Acknowledgement of Learner Identity}

The theory of identity is introduced by Norton in 1998, she considers that the identity of the language learner addresses the ways in which language learners understand their relationship to the social world, how that relationship is constructed across time and space, and how the learner understands possibilities for the future. And the learner's investment in language learning depends on the acknowledgement of their identity. Or in other words, if the identity is confirmed and shared with both teachers and learners, they all, the teachers and learners, will invest more in the language efforts.

\section{Implication}

The outcome of the research can serve as a guide line for the ones who want to build a similar mobile-based learning community in other disciplines. There are some helpful suggestions can be derived from this research outcome, such as student preference of mobile-based activities and task type, how to get more out of mobile in language learning or learning in other disciplines, and how to make good use of mobile to work as a good autonomous learning tool.

Secondly, there is a pity that the mobile learning community should be built on a software which is specially designed to language learning and teaching purposes. But there is nowhere to find such a software in China. The author has an ambition that maybe the result of the research such as the mobile-based learning manner of students and recommended teaching and learning activities will be helpful for the software technicians to design successful application software for mobile-based language learning. And the results of the study suggest that the app in business English learning should have the following features: 
(1) The texts chosen for business English reading app should be short (less than 80 words), both in Chinese and English, purpose-designed and task-based;

(2) The topics chosen for business English speaking app should be practical and can be traced back to learner's life;

(3) The design of the teaching video. The classic example of teaching video is the videos designed by Salman Khan from Khan Academy. In his video, there is no face of the teacher but a hand with a chalk writing along with the monologue explanation until the chalk handwriting filled with the screen. Mr Khan believed that students will be distracted by the facial expressions and movements of the teachers especially when they learn independently;

(4) The time of each video. The shared feature of the video designed by Salman Khan or Jonason Belman is short and focused. The videos last for several minutes and 10 minutes tops. Each video focuses on one topic which fits well with the attention span of students.

\section{Conclusion and Limitation}

Whilst these conclusions are based on subjective interpretation (open questions in the questionnaire) and objective data (participation records and quiz results), the author is aware that this research has some limitations. Firstly, when the author acquires students' perception toward MALL community, some emotional factor may bias the survey results. Secondly, the perception of the learners toward the MALL community maybe twisted by their personal feeling toward the course and the teacher.

Despite some limitations, the analyses in this study show that the learners' participation on MALL community was positively correlated with their business English reading and speaking skills. Learners have a position attitude toward the mobile-based learning community. This finding was further supported by that the learners are willing to work together with teachers to improve the community and their decision to continue to use the community in their further study.

Overall, MALL language community is a positive example of MALL as it was perceived by students as a useful learning application in a business English class. WeChat was regarded as beneficial in helping learners raise their metalinguistic awareness and improve their business awareness in tackling the business English problems. Continued research and development in the realm of MALL is necessary as it will help illuminate helpful factors for the development of a language learning specific application.

\section{References}

Bates, A. W. T. (1997). The impact of technological change on open and distance learning. Distance Education, 18(1), 93-109.

Berge, Z. (1995). The role of the online instructor/facilitator. Educational Technology, 35(1), 22-30. Retrieved from http://www2.nau.edu/ mpc3/moderate/teach_online.html

Campbell, A. P. (2003). Blogs for use with ESL classes. Retrieved from http://iteslj.org/Techniques/Campbell-Blogs.html

Chinamobile. (2012). Retrieved from http://www.10086.cn/bj/

Colpaert, J. (2004). From courseware to coursewear? Computer Assisted Language Learning, 17(3-4), 261-266.

Comas-Quinn, A., \& Mardomingo, R. (2009). Mobile blogs in language learning: Making the most of informal and situated learning opportunities. ReCALL, 21(1), 96-112.

Corden, R. E. (2001). Group discussion and the importance of a shared perspective: Learning from collaborative research. Qualitative Research, 1(3), 347-367.

Harasim, L. M., Hiltz, S. R., Teles, L., \& Turoff, M. (1995). Learning networks: A field guide to teaching and learning online. Cambridge, MA: MIT Press.

Holec. H. (1981). Autonomy and foreign language learning. Oxford: Pergamon Press; Strabourg, Council of Europe. 
Hsu, S. Y. (2005). Building language-learning environments to help technological university students develop English independent learning. JALT CALL Journal, 1(2), 51-66.

Kennedy, C., \& Levy, M. (2008). L'italiano al telefonino: Using SMS to support beginners’ language learning. ReCALL, 20(3), 315-330.

Li, Z., \& Hegelheimer, V. (2013). Mobile-assisted grammar exercise. Language Learning \& Technology, 17(3), 135-156.

Liu, T. Y., \& Chu, Y. L. (2010). Using ubiquitous games in an English listening and speaking course: Impact on learning outcomes and motivation. Computers \& Education, 55(2), 630-643.

Nonnecke, B., \& Preece, J. (2003). Silent participants: Getting to know lurkers better. In C. Leug and D. Fisher (Eds.), From Usenet to CoWebs: Interacting with social information spaces. Amsterdam, Holland: Springer-Verlag.

Norton, B. (2000). Identity and language learning: Gender, ethnicity, and educational change. Harlow, England: Longman/Pearson.

Palincsar, A. S. (1998). Social constructivist perspectives on teaching and learning. Annual Review of Psychology, 49, 345-375.

Panitz, T. (1996). A definition of collaborative versus cooperative learning. Deliberations. Retrieved from http://www.londonmet.ac.uk/deliberations/collaborative-learning/panitz-paper.cfm

Rueckert, D., Kiser, R., \& Cho, M. (2012). Oral language assessment made easy via VoiceThread! Proceedings from TESOL International Convention and English Language Expo. March 28-31, Philadelphia, PA.

Sfard, A. (1998). On two metaphors for learning and the danger of choosing just one. Educational Researcher, 27(2), 4-13.

Stockwell, G. (2010). Using mobile phones for vocabulary activities: Examining the effect of the platform. Language Learning \& Technology, 14(2), 95-110.

Sung, Y. T., Huang, C. C., \& Chang, K. E. (2006). The design and application of a mobile devices-based real time formative assessment system. Proceedings from the Meeting of the IADIS International Conference Mobile Learning. July, Dublin, Ireland.

Wang, S., \& Higgins, M. (2006). Limitations of mobile phone learning. The JALT CALL Journal, 2(1), 3-14.

Wang, S., \& Smith, S. (2013). Reading and grammar learning through mobile phones. Language Learning \& Technology, 17(3), 117-134.

Zhang, H., Song, W., \& Burston, J. (2011). Reexamining the effectiveness of vocabulary learning via mobile phones. TOJET: The Turkish Online Journal of Educational Technology, 10(3), 203-214. Retrieved from http://www.tojet.net/articles/ v10i3/10323.pdf 